\title{
Angiofibroma, a rare cardiac tumour in children
}

\section{G Gayen, ${ }^{1}$ A Pan, ${ }^{2}$ K Dasbakshi, ${ }^{3}$ P Mukherjee ${ }^{4}$}

${ }^{1}$ RMO Cum Clinical Tutor, Department of pediatrics, National Medical College, Kolkata. ${ }^{2}$ Lecturer Department Of Paediatrics, college of Medical Sciences,Bharatpur, Nepal . ${ }^{3}$ Assistant Professor, ${ }^{4}$ Professor, Department of cardiothoracic surgery, National Medical College, Kolkata

\begin{abstract}
Angiofibromas, located in any other sites than nasopharynx are unusual. Cardiac angiofibromas are a very rare cardiac tumours in comparison to rhabdomyomas which are the commonest in the children. We report a right ventricular tumour in a10 year old girl which was excised under cardiopulmonary bypass successfully and diagnosed as angiofibroma on histopathology.
\end{abstract}

\section{Key words: Angiofibroma, cardiac, children.}

\section{Introduction}

Angiofibromas are benign but locally aggressive vascular tumours that occurs in nasopharynx, neck and face. These are rare soft tissue hamartomas which contain mainly blood vessels and fibrous tissues often found in association with tuberous sclerosis (TS). Angiofibromas located in other sites than head and neck regions are rare and as cardiac tumours in children these are even rarer in comparison to rhabdomyomas which are the commonest in children. We report a case of cardiac angiofibroma in a 10 years old girl who presented with frequent chest pain and fatigue for the last two years. Echocardiography with Doppler study showed a space occupying lesion in the right ventricular outflow tract. It was operated and found to be angiofibroma on histopathology. The child is now well on follow up.

\section{Case report}

A 10 year old girl was admitted in our department with the symptoms of frequent chest pain and fatigue and shortness of breath for the last two years. There was no history of cyanosis, or easy fatigability after birth. There was no such family history in the parents and siblings. There was no history of mental retardation, seizure disorder, any skin lesion suggestive of TS. She was normotensive, with a pulse rate of 80 per minute. There was right ventricular heave and an ejection systolic murmur. Electrocardiogram showed right ventricular strain pattern. Chest $\mathrm{X}$ ray showed normal cardio thoracic ratio. Haemogram and blood biochemistry were within normal limits. Echocardiography with Doppler study showed a space occupying lesion in the right ventricular outflow tract moving in and out of the RVOT in systole and diastole 
and was diagnosed as a pedunculated right ventricular (RV) tumour. Gradient across the pulmonary valve was $80 \mathrm{mmHg}$ (systolic). Pediatric cardiologist and cardiothoracic surgeon were consulted and the tumour was excised. Median sternotomy was done, aortic and bicaval cannulation made to put the patient on cardiopulmonary bypass. Aorta was cross clamped, cardioplegic arrest of heart achieved and pulmonary arteriotomy was made. The solid tough pedunculated $3 \mathrm{~cm}$ X $2 \mathrm{~cm}$ rounded mass was excised from the subvalvular area below the pulmonary artery. It was attached to the inter ventricular septum near the right ventricular outflow tract with a base which was about $0.5 \mathrm{~cm}$ wide. It was completely excised and there were no residual tumour anywhere else. The clamp time was 15 minutes. Weaning off bypass, decannulation and closure and recovery was uneventful. The histopathology was reported as angiofibroma.

The patient is doing well after a one year follow up. Echocardiography done 8 months after operation was normal without any right ventricular obstruction.

Figure 1.Echocardiography showing the mass

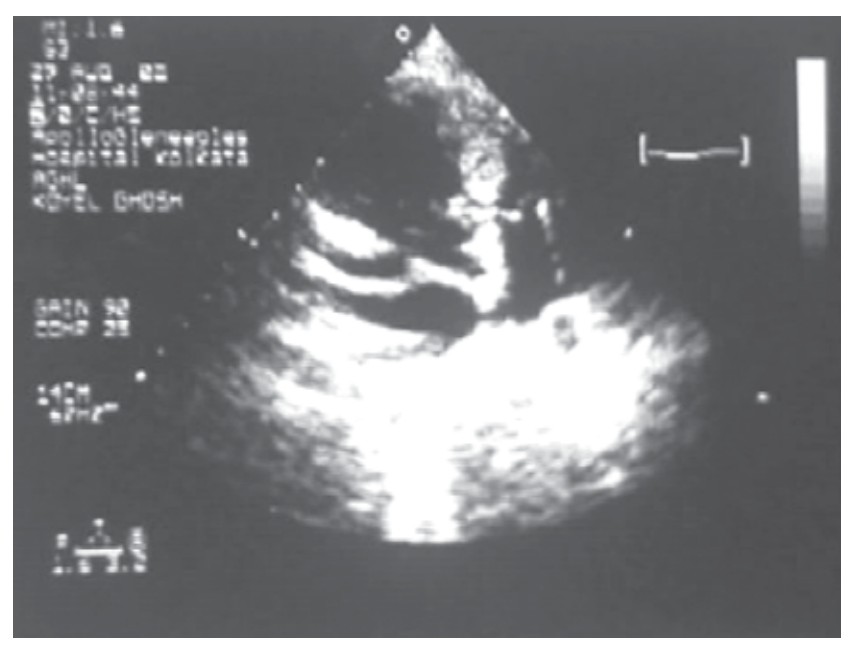

Figure 2: Echocardiography with colour doppler showing the mass

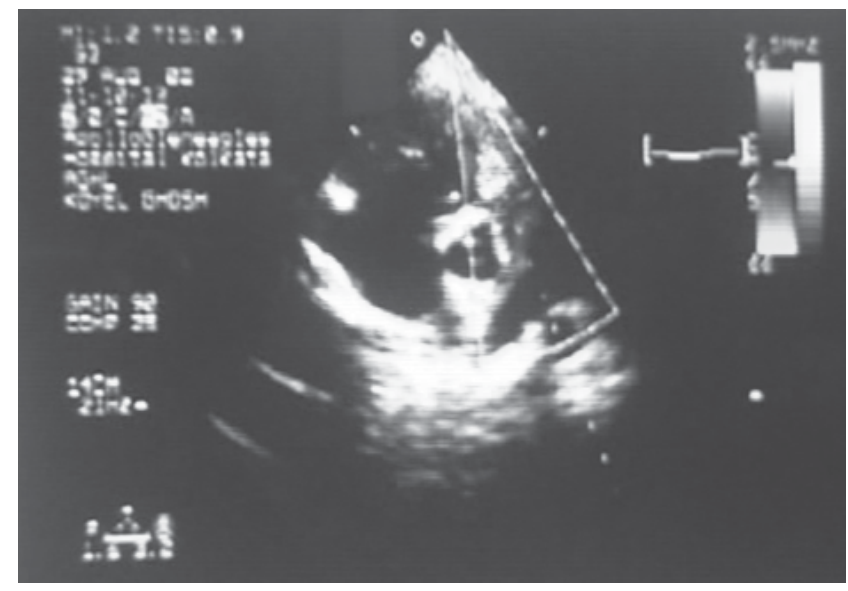

Figure 3: Excised tumour mass

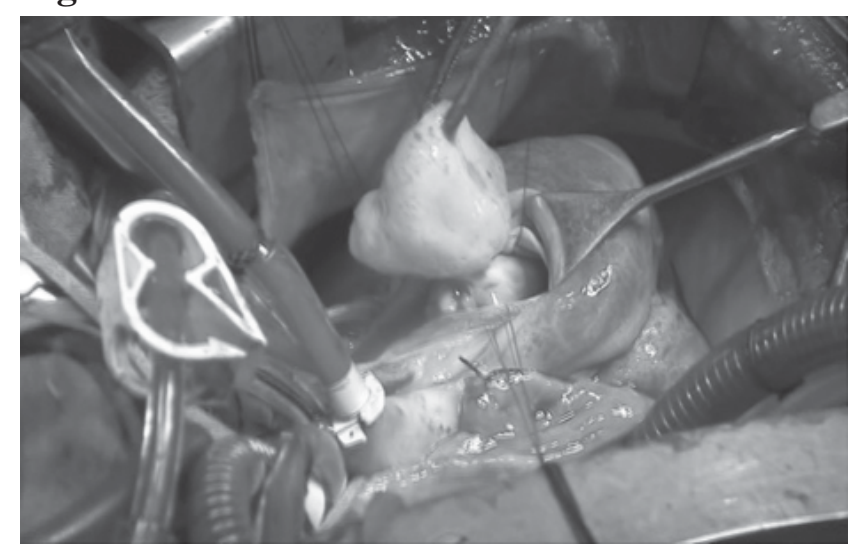

Figure 4: Histopathology of the excised mass

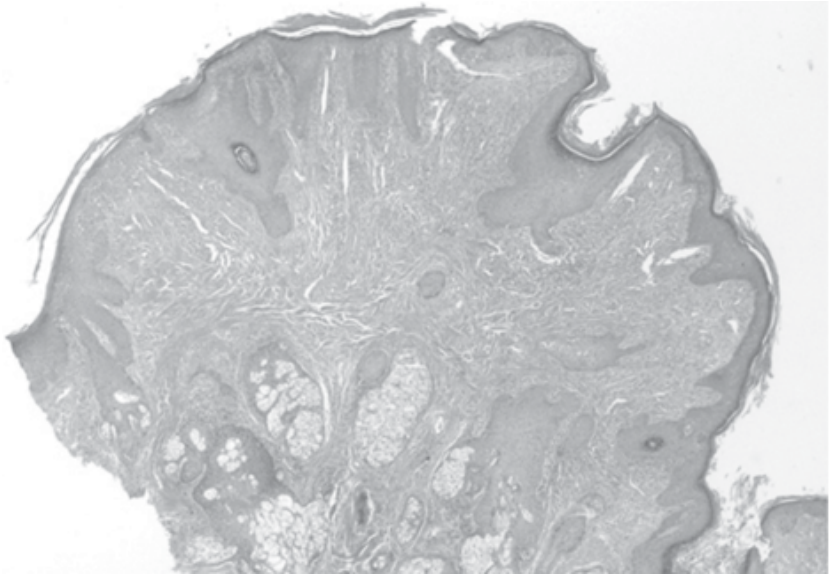

\section{Discussion}

Primary cardiac tumors are rare in children. The majority are benign and noninvasive, although they may have significanthemodynamic consequences depending 
$G$ Gayen et al. Angiofibroma, a rare cardiac tumour in children

on their location. By far, the most common type of tumors reported in children and adolescents is rhabdomyoma,and in $50 \%$ case it is associated with tuberous sclerosis complex. ${ }^{1}$

Other benign tumours are fibroma, myxoma, and teratoma. ${ }^{2}$ Sarcoma is the largest group of primary cardiac malignant neoplasms. ${ }^{3}$ Angiofibroma is rare to present as cardiac tumour. Its usual location is mainly the nasopharynx and head and neck region where it presents with nasal obstruction and nose bleeds. It is most common in adolescents male(peak age15 yrs) and thus is sometimes referred to as a juvenile nasopharyngeal angiofibroma. ${ }^{4}$ Under the microscope, these tumors are well-circumscribed but unencapsulated and composed of collagenized fibrous stroma with vessels ranging from small slit-like spaces to dilated lumens. No significant cytologic atypia is observed. Occasional multinucleated stromal cells are present. ${ }^{5}$ The vascular nature is highlighted by angiograms showing a rich supply. Cardiac angiofibroma is very rare, Previously only two cases were reported as epicardial angiofibroma in a fetus with Beckwith-Wiedemann syndrome ${ }^{6}$ and angiofibroma of the tricuspid valve as a presentation of the tuberous sclerosis complex ${ }^{7} \mathrm{TS}$ is usually associated with facial angiofibroma or adenoma sebaceum. ${ }^{8}$ In our case the tumour was located in the RVOT. There was no associated features suggesting tuberous sclerosis, it was a sporadic case. The clinical presentation of a patient with a cardiac tumor is determined more by the tumor's location than by its histologic type, varying widely from asymptomatic presentations to life-threatening cardiac events by critical obstruction of a valve or outflow tract and causing arrhythmia. Because of the rapid growth of tumor mass in small-sized cavities, congestive heart failure has been frequently reported in childhood and surgical treatment is lifesaving. Right-sided tumors may present with congestive heart failure (CHF) manifested by fatigue, edema, jugular venous distention, and ascites. Other symptoms include shortness of breath, syncope, and night sweats. Pericardial effusions may occur. Vena cava syndrome, pulmonary embolism, and restrictive cardiomyopathy are some of the complications. Left atrial and left ventricular tumors can present with fever, chills, dizziness, dyspnea on exertion, cold sweats during exercise or at night, and nonproductive cough. Because tumors may embolize, they also can lead to seizures, transient ischemic attacks, and cerebrovascular and peripheral-vascular accidents. Based on their size and position, they may induce arrhythmias and interfere with ventricular compliance. Our child presented with the features of right sided outflow tract obstruction. Echocardiography with doppler is an excellent tool to diagnose the tumour and gradient if any obstruction. However, precise information on the tumor histotype is not attainableby echocardiography. ${ }^{9}$ A correct therapeutic plan requires an accurate histopathologic diagnosis of the resected mass to rule out the rare case of a malignancy, CT scan, MRI , ECG can add to the diagnosis. In our child ECG, CXR were done and there was no rhythm abnormality.The mode of treatment varies and cannot be easily simplified because the kind of tumor (benign/ malignant, infiltrative/ localized) dictates therapy. Location and extent of the tumor, as well as symptoms, are clinical variables that direct treatment. Observation is sufficient when the mass is small and does not interfere with vascular hemodynamics. However, when the tumor is causing hemodynamic problems by either obstructing the outflow tract, valve or causing rhythm 
abnormalities, aggressive management by surgical intervention should be done. In occasional cases, implantation of a pacemaker may be needed if atrioventricular block occurs. In our child it was excised successfully under cardiopulmonary bye pass, On follow up the child was normal and repeat echocardiography after 8 months show no further obstruction of RVOT.

\section{References}

1. Bass JL, Breningstall G, Swaiman K.F. Echocardiographic incidence of cardiac rhabdomyoma in tuberous sclerosis. Am J Cardiol 1985:55:1379-82.

2. Beghetti M, Gow RM, Haney I, Mawson J, Williams WG, Freedom RM. Pediatric primary benign cardiac tumors. a 15 year review. Am Heart J 1997;134: 1107-14

3. Becker AE. Primary heart tumors in the pediatric age group: a review of salient pathologic features relevant for clinicians Pediatr Cardiol. 2000;21(4):317-23.
4. Biller HF. Juvenile nasopharyngeal angiofibroma. Ann Otol Rhinol Laryngol 1978;87:630-2.

5. Batsakis JG. Tumors of the head and neck: clinical and pathological considerations. 2a ed. Baltimore, MD: Williams \& Wilkins; 1979; 296-300.

6. Satgé D, Vidalo E, Desfarges F, A third case of cardiac neoplasm in a fetus with BeckwithWiedemann syndrome: epicardial angiofibroma. Fetal Diagn Ther. 2005;20(1):44-7.

7. Jutley RS, Janas R, Matuszewski M, Angiofibroma of the tricuspid valve: a rare presentation of the tuberous sclerosis complex J Cardiovasc Surg (Torino). 2006;47(4):481-2.

8. Paller AS, Goldsmith LA. Tuberous sclerosis complex. In: Freedberg IM., Eisen AZ, Wolff K, Austen KF, Goldsmith LA, Katz SI, eds. Fitzpatrick2 s Dermatology in General Medicine. $6^{\text {th }}$ ed. New York, McGraw-Hill; 2003:1822-25,

9. Burke A, Jeudy J Jr, Virmani R. Cardiac tumours: an update. Heart. 2008;94:117-23. 


\section{Journal of College of Medical Sciences}

\section{Instruction to Authors}

The Journal of College of Medical Sciences (JCMS-Nepal) welcomes contributions for publication of original articles, case reports, short communications, review articles, letter to the editor and book reviews on all topics of Biomedical Sciences. The manuscripts should be submitted as described below:

1. Covering letter addressed to the Chief Editor by the corresponding author.

2. Declaration signed by all authors mentioning that the work has not yet been published or sent for publication elsewhere.

3. Three sets of manuscript (including original copy).

4. Manuscript has to be send in an CD and also via E-mail.

Note: 1,2 \& 3 to be submitted either by courier, post or personally to the 'Chief Editor Journal of College of Medical Sciences, Bharatpur, Nepal.’ P.O. Box No.23 (E-mail: infojcms@gmail.com)

\section{Preparation of Manuscript}

A. Format: The article should be typed or printed in Ms-Word format using Times New Roman font (Size-12) double-space with margins of at least $2.5 \mathrm{~cm}$ on both sides. The manuscript is to be arranged as given below.

B. Title: (Heading in bold letters), without any abbreviation, authors name(s) as in the declaration form, complete address of the corresponding author, Postal address, Phone number, E-mail address.

Note: Title should be simple, brief, self explanatory and should not include abbreviations.

C. Abstract and key words: Abstract should be not more than 250 words and it should be concise and high light the main aim of study mentioning the basic procedures, main findings and the major conclusions. It is suggested in general to write as Objective, Material and methods, Results and Conclusion. There should be 3-6 key words.

D. Text: The main text in case of research papers should be divided into sections with following headings as given below 1-6. Text for original article should not be more than 3500 words, Case report not more than 600 words, Review article not more than 4500 words Letter to the editor not more than 500 words and Book reviews not more than $\mathbf{5 0 0}$ words. Conclusion should be linked with the goals of the study and supported by the results reported in the paper.

1. Introduction: It should contain brief background and purpose of study undertaken.

2. Materials and methods: This section should mention how the work was carried out, sufficient procedure adopted in detail(s) and allow the experiment to be interpreted and repeated by readers. Methods should contain detail procedure of data collection, standard scientific methods like statistical evaluation with references which were previously published.

Note: Author should give the description of modifications of new methods so that readers can judge their accuracy, reproducibility and reliability.

3. Results: It should be written concisely with appropriate figures and tables. There should be no duplication of results in both tables and figures. Appropriate foot notes and statistical methods should be mentioned in the tables. 
4. Discussion: Interpretation of results should be given in lieu of recapitulation. Authors should compare the results with previous existing literature and discuss the clinical and scientific implications of theor research. Authors should consider only those published articles directly relevant to interpreting their results and placing them in context.

5. Conclusion: Attention should be given to the usefulness of the study. Authors should provide only conclusions of the study directly supported by the results, along with implications for clinical practice, avoiding speculation and overgeneralization. Indicate whether additional study is required before the information should be used in usual clinical settings. Give equal emphasis to positive and negative findings of equal scientific merit.

6. Acknowledgement: Authors can acknowledge only person(s), who contributed to this work or provided financial or technical support.

E. References: Authors should not use the endnote or footnote function of word processing software to generate a list of references. The number references (including references to unpublished information) should be listed consecutively in the order of their appearance in the manuscript. Authors should type a list of references in their order mentioned in the text, not alphabetically, at the end of the manuscript. If there are more than 3 authors, list the first 3 authors, followed by comma and "et al." should be in italic. It is suggested to refer http://www.icmje.org/ index.html. Accuracy of citations is the author's responsibility. Examples of correct referencing forms are as follows:

Journal Article: Name of author (s): title of the paper, name of journal in italic, year, volume in bold (issue no if any eg. (1), page first to last. Example: Smith CR, Thapa A, Chen AHM, et al. Gender-associated differences in emergency department pain management. Ann Emerg Med 1995; 26: (1) 414-21.

Book: Name of author(s), title of the subject, name of the book, edition number, place of publication, name of the publisher, year, page first to last. Example: Tierney LM, McPhee SJ, Papadakis MA, Thapa A, Current medical diagnosis and treatment, 14 ${ }^{\text {th }}$ edi. New York, Lange Medical Books. 2001:834-40.

Book Chapter: Mengert TJ, Eisenberg MS. Prehospital and emergency medicine thrombolytic therapy. J.E. Tintinalli, E. Ruiz, R.L. Krome. Emergency Medicine: A Comprehensive Study Guide. $4^{\text {th }}$ edi. New York: McGrawHill; 1996:337-43.

Periodicals: Ray A, Henke PG. Gulati K, Sen P. The amygdaloid complex, corticotrophine releasing factor and stress ulcer formation in rats. Brain Res 1993; 624: 286-90.

Courses, lectures (unpublished): Sokolove PE. Needlesticks and high-risk exposure. Course lecture presented at American College of Emergency Physicians, Scientific Assembly, October 12, 1998; San Diego, CA.

Internet: Gore L. ACEP hails House passage of the HEALTH Act [press release]. American College of Emergency Physicians Web site. Available at: http://www.acep.org/1,32181,0.html. Accessed March 14, 2003.

Personal Communication: Avoid reference to personal communications, but when necessary, include the name of author(s), his or her title, month, and year. A letter granting permission to publish from the person providing the information must be included at the time of submission.

Tables: Number the tables has to be mentioned consecutively under 'results' section. Each table has to be referred consecutively in the results (not after references).

Figures: Figures (charts, graphs, photographs, etc.) and legends should be self-explanatory and able to standalone. The data presented in a figure should not be duplicated in the text. Authors should refer to each figure consecutively in the text and each figure should be submitted as a separate file.

Proofs: Will be sent to authors for final check up. Authors are solely responsible for any mistake in technical and bibliographic presentations. The editors shall have the right to edit, condense, alter, rearrange or rewrite articles before publication without referring to the authors concerned. The editorial board has the right to reject or accept paper at any stage of publication. The decision of the editorial board shall be final. 